\title{
Principal modeling of technological support for sustainable construction projects
}

\author{
Sergei Beliakov ${ }^{1, *}$ \\ ${ }^{1}$ Moscow State University of Civil Engineering, 26, Yaroslavskoye Shosse, Moscow, 109377, Russia
}

\begin{abstract}
The rationale for the choice of technological solutions in the framework of construction design is largely interrelated with the effectiveness of solving problems that arise during the stages of the project life cycle. The modeling of the project's technological support is based on a systematic approach, which is a connecting element between various tools and techniques by presenting the project's processes in the context of the life cycle, as well as their mutual correlation with technological solutions. This approach eliminates the adoption of chaotic decisions in the process of project development, since its implementation occurs directly at the initiation stage. As part of a comprehensive solution to this task, a system of principles of technological support for construction projects has been developed, including the principles of unity, balance, compliance and synergy. The results obtained in the framework of the study, the key of which are the scheme of principal modeling of technological support for construction projects and the algorithm for modeling technological support for construction projects, develop approaches to scientific and methodological approaches to managing the effectiveness of investment and construction activities in general and, in particular, to the development and justification of design solutions for construction. The key aspect of the implementation of the developed algorithm is the analysis of processes, for the methodological support of which it is proposed to use the unified form "Card determinant of the technological solution". Practical application of the results obtained in the framework of the research can be carried out in a number of areas within the processes and procedures of investment and construction design, development of project documentation, construction consulting, technological engineering, financial and technical supervision and audit
\end{abstract}

\section{Introduction}

The effectiveness of a construction project is influenced by a large number of heterogeneous limiting factors. When finding the necessary balance between these factors, it becomes possible to obtain higher project performance indicators. This hypothesis implies that the overall performance will depend on the rationality of the chosen concept

\footnotetext{
*Corresponding author: serj-bel@yandex.ru
} 
and the correct allocation of resources, which will allow us to achieve an equilibrium of limiting factors [1-4].

A superficial analysis of the list of technological solutions and methodological tools currently used in the planning and implementation of construction projects demonstrates the breadth of the scope of the tasks to be solved and the complexity of their structuring:

- Big data technologies;

- GIS technologies;

- Best-use-analysis;

- Due diligence;

- SWOT analysis;

- Methods of risk analysis;

- Pricing methods;

- ERP systems;

- Methodology for maintaining a set of project documentation;

- Accounting and planning system;

- Updating and evaluation system;

- Contract bidding system;

- Public services;

- The system of project meetings;

- BIM;

- PDM system;

- Autodesk Navisworks;

- Cloud technologies ;

- Mystery shopper (mystery shopper);

- CRM systems.

The choice of methods and tools depends on the planned result of solving problems that arise during the stages of the project life cycle. Due to the multi-stage nature of the construction project, as well as the presence of a huge number of tasks that arise in the process of its development, many technologies are needed to provide an optimal solution to these problems [5-7]. The selection of specific methods and tools for achieving the goals of the process stages requires the use of a systematic approach that allows you to:

- identify the need for technology;

- to establish criteria for their selection;

- make their mutual arrangement in relation to the tasks processes and stages of the project;

- assess their impact on the resulting performance of the project;

- effectively carry out operational activities.

This approach eliminates the adoption of chaotic decisions in the process of project development, since its implementation occurs directly at the initiation stage. Thus, as a result of applying a systematic approach, the occurrence of areas of inefficiency is minimized, since throughout all stages of the project, this technique involves the implementation of a systematic analysis of management decision-making. The technological solutions chosen to solve the problems that arise during the processes of individual stages of a construction project are only an addition to the general concept of effective management of an investment and construction project [8-11]. 


\section{Materials and Methods}

The modeling of the technological support of the project is based on a systematic approach, which is a link between various tools and techniques, for example, by presenting the project processes in the context of the life cycle, as well as their mutual correlation with technological solutions. The proposed method allows you to model complex business processes in the form of a visual illustration by means of a matrix consisting of a table of stages, tasks, areas of inefficiency and methods and tools that allow you to solve these problems and minimize areas of inefficiency (Fig. 1). It is important to note that for visualization of the analysis of the solution of individual tasks or consideration of stages, it is possible to use any means that allow you to visually interpret the processes taking place, for example, in the form of flowcharts, diagrams, text descriptions $[12,13]$. The basis of this system is constant analysis, contributing to achieve the visions of submission of the project, as well as the reduction of uncertainty, thereby increasing the range of information organization-wide coverage, and responsiveness to changes in project speed and decisionmaking [14-16].

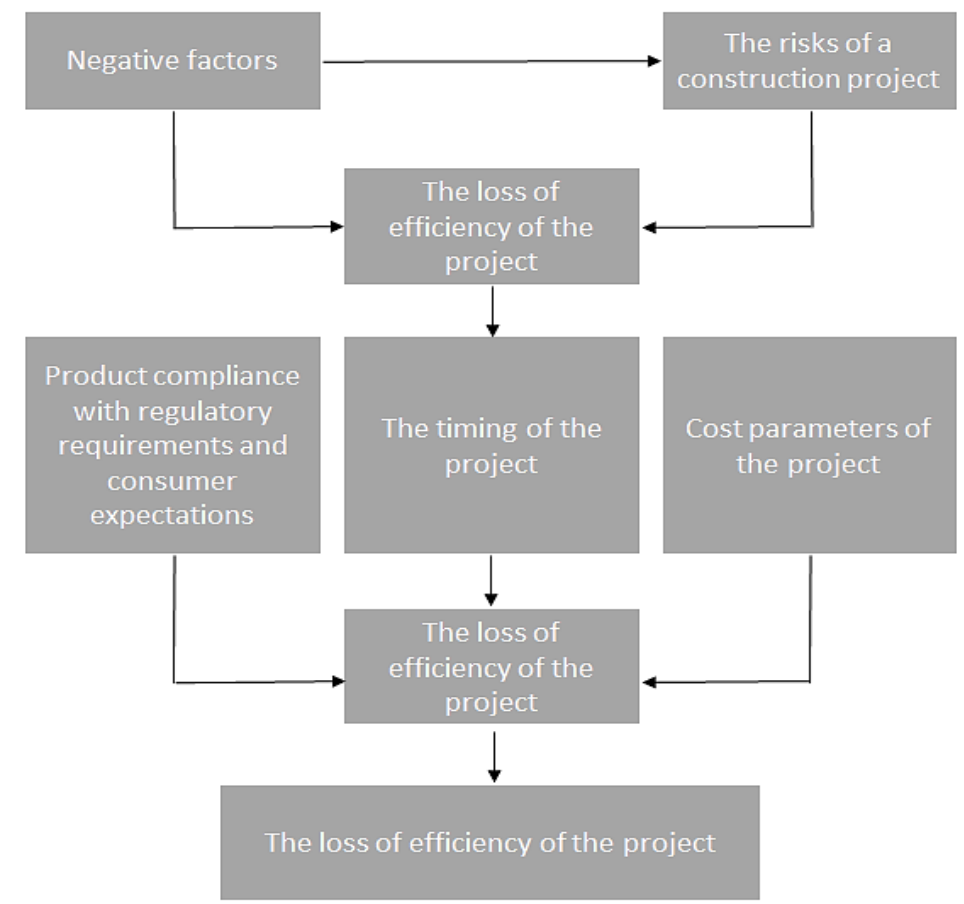

Fig. 1. Conceptual prerequisites for fundamental modeling of technological support for construction projects. 


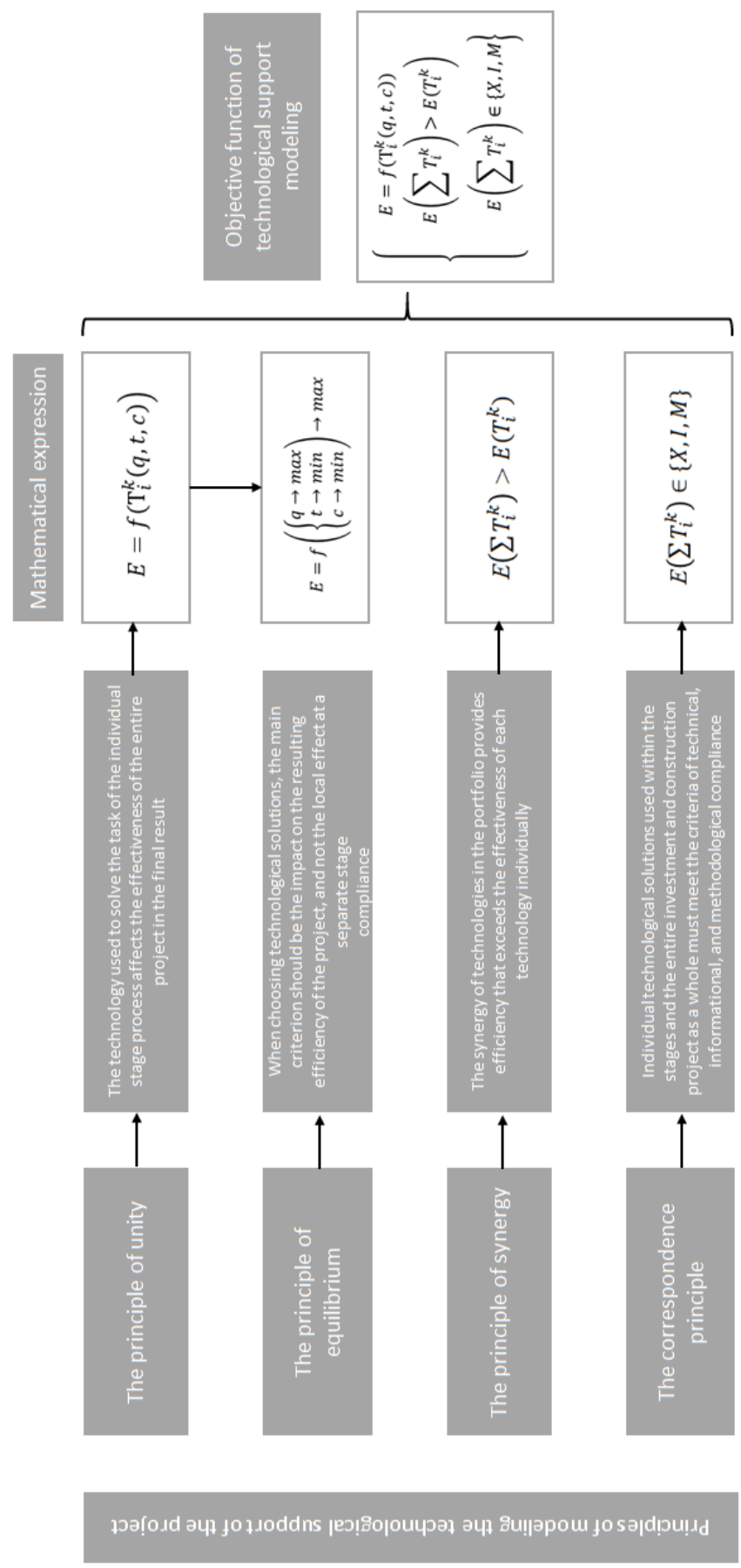

Fig. 2. Scheme of principal modeling of technological support for construction projects.

As part of a comprehensive solution to this task, a system of principles of technological support for construction projects has been developed, including the principles of unity, balance, compliance and synergy. The scheme of basic modeling of technological support for construction projects, including formalized expressions of these principles and an integral objective function, is shown in Figure 2. 


\section{Results}

Starting from the stage of justification of the choice of alternative technological solutions, it is necessary to be guided by a system of principles that ensure the implementation of the main task of technological support - improving the effectiveness of the construction project. The algorithm for modeling the technological support of the construction project is shown in Figure 3.

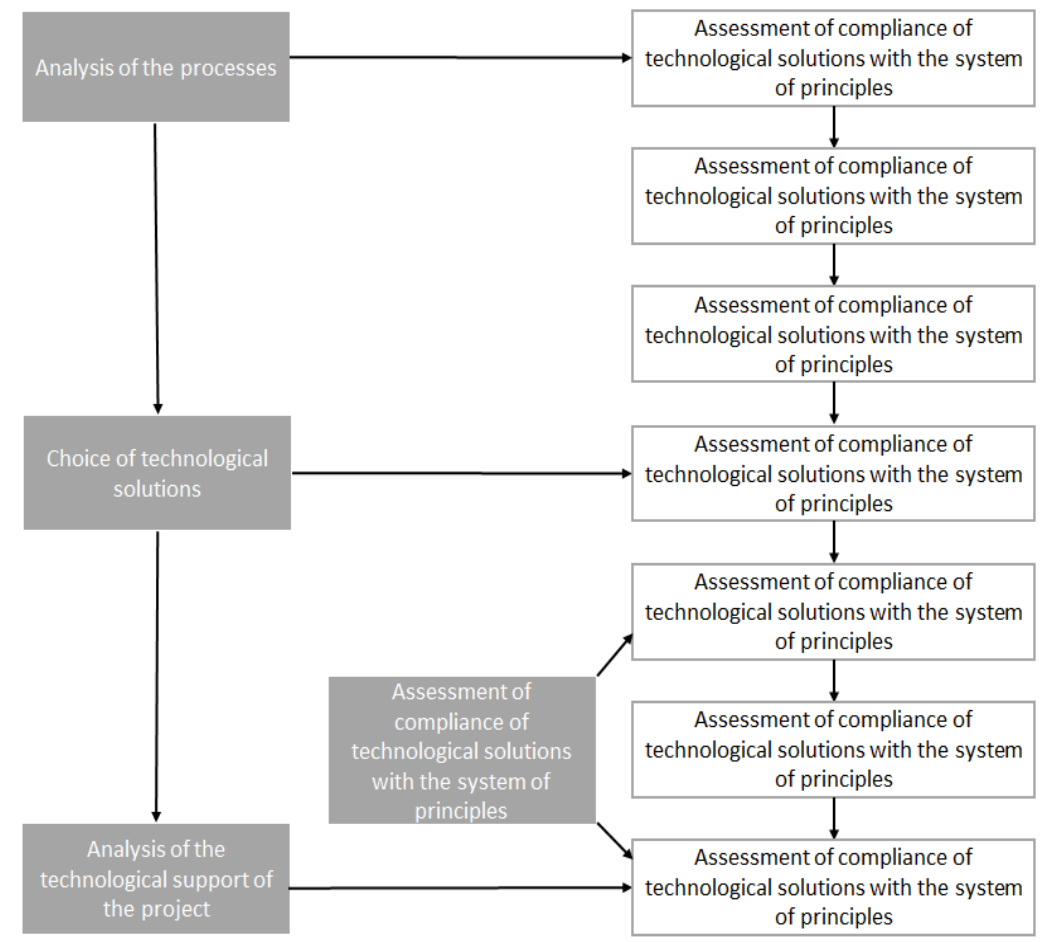

Fig. 3. Algorithm for modeling the technological support of the construction project.

The key aspect of the implementation of the above algorithm is the analysis of the processes in the first stage. In order to provide methodological support for this procedure, it is proposed to use the unified form "Card determinant of the technological solution" (Table $1)$.

In accordance with the proposed algorithm, the first stage of modeling the technological support of a construction project is the analysis of the processes of individual stages of the life cycle of an investment and construction project. As a result of the analysis of the life cycle of the development project, a complete list of stages, processes, tasks, as well as areas of inefficiency that hinder the development of the project should be presented. For the convenience of the analyzer, the data can be consolidated into a "Summary table of technological support". Thanks to the applied indicators, it becomes possible to determine the impact of areas of inefficiency on the tasks of the processes of individual stages. The column "Technological and methodological support" presents technologies and approaches that allow you to select the appropriate technology or methods to achieve the results of processes and eliminate areas of inefficiency. For the greatest clarity, after this column, there are similar indicators that allow you to correlate these technologies with tasks and factors of influence. Thus, this unified tabular form allows us to proceed to the second step 
of the technology selection stage - the evaluation of the most suitable technologies, according to the proposed algorithm.

Table 1. Card determinant of the technological solution.

\begin{tabular}{|l|l|l|}
\hline \multicolumn{2}{|c|}{ Name of the technological or methodological solution } \\
\hline \multirow{3}{*}{$\begin{array}{l}\text { The principle } \\
\text { of unity }\end{array}$} & $\mathrm{q} \rightarrow \max$ & $\begin{array}{l}\text { The degree of compliance of products with the } \\
\text { requirements of regulatory documentation and consumer } \\
\text { expectations }\end{array}$ \\
\cline { 2 - 3 } & $\mathrm{t} \rightarrow \min$ & The timing of the project \\
\cline { 2 - 3 } & $\mathrm{c} \rightarrow \min$ & The cost part of the project \\
\hline The principle of synergy & $\begin{array}{l}\text { Synergy of technological solutions provides efficiency } \\
\text { that exceeds the efficiency of each technology } \\
\text { individually }\end{array}$ \\
\hline \multirow{2}{|c|}{ The principle of equilibrium } & $\begin{array}{l}\text { When choosing technological solutions, the main criterion } \\
\text { should be the impact on the resulting efficiency of the } \\
\text { project, and not the local effect at a separate stage }\end{array}$ \\
\hline \multirow{2}{|c|}{$\begin{array}{l}\text { The } \\
\text { correspondence } \\
\text { principle }\end{array}$} & Technical & Technical features of the described technological solution \\
\cline { 2 - 3 } & Information & $\begin{array}{l}\text { Feasibility of implementation, taking into account the } \\
\text { information obtained from the use of a technological } \\
\text { solution or methodology }\end{array}$ \\
\cline { 2 - 3 } & Methodological & Experience in implementing a technology or methodology \\
\hline \multicolumn{2}{|c|}{ Compliance with the project's technological support criteria } \\
\hline \multicolumn{2}{|c}{}
\end{tabular}

\section{Conclusions}

The results obtained in the framework of the study, the key of which are the scheme of fundamental modeling of technological support for construction projects and the algorithm for modeling technological support for construction projects, develop approaches to scientific and methodological approaches to managing the effectiveness of investment and construction activities in general and, in particular, to developing and justifying design solutions for construction in terms of technological support at the early stages of the project life cycle. The improvement of this methodological toolkit in the future can be aimed at clarifying the list of criteria for evaluating and comparing technological solutions.

Practical application of the results obtained in the framework of the research can be carried out in a number of areas within the processes and procedures of investment and construction design, development of project documentation, construction consulting, technological engineering, financial and technical supervision and audit, etc. (Figure 4). 

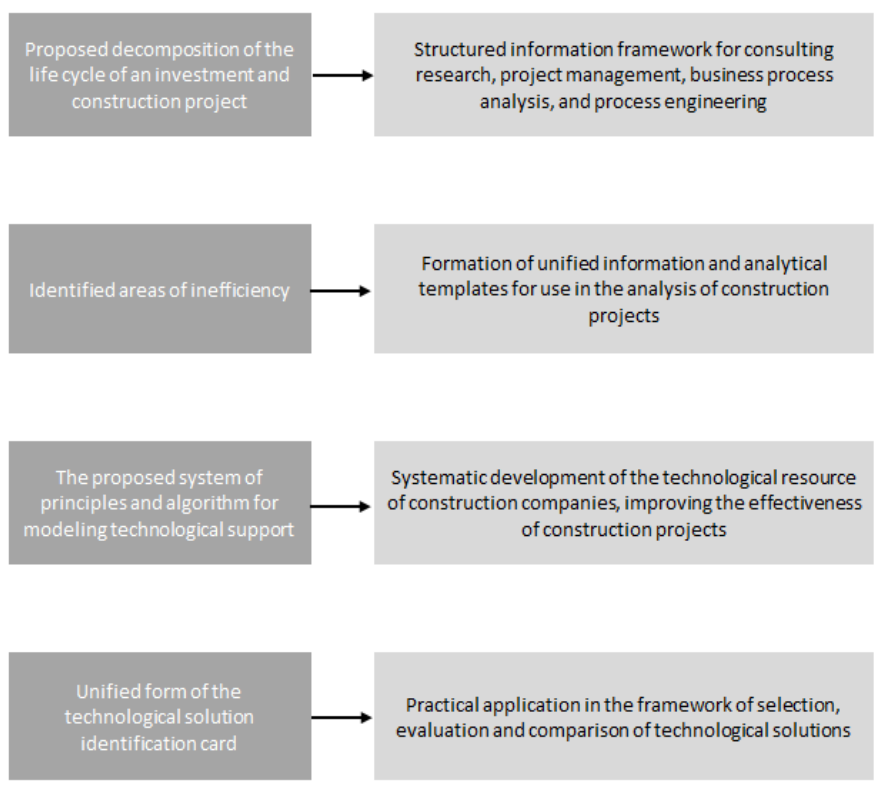

Fig. 4. Directions of practical application of the research results.

\section{References}

1. S.E Ahmed,S.M. El-Sayegh, Buildings 11(1), 1-25 (2021)

2. S. Sinenko, IOP Conference Series: Earth and Environmental Science 459(5), 052043 (2020)

3. L.B. Zelentsov et al., IOP Conf. Series: Materials Science and Engineering 698(7), 077052 (2019)

4. C. Marcher et al., Lecture Notes in Computer Science 11792, 229-235 (2019)

5. A.C.M. Moura, M. Campagna, Disegnarecon 11(20), ED.1-ED.3 (2018)

6. S. Sinenko, IOP Conference Series: Materials Science and Engineering 365(6), 062039 (2018)

7. C. Zanchetta, Techne 13, 329-336 (2017)

8. F. Yao et. al., Automation in Construction, 123, 103537 (2021)

9. A.A. Ermakov et al., IOP Conf. Series: Materials Science and Engineering 952(1), $012024(2021)$

10. I. Vladimirova et al., Advances in Intelligent Systems and Computing 1258, 601-615 (2021)

11. D. Li, Advances in Intelligent Systems and Computing 1234, 180-184 (2021)

12. M. Zubizarreta et al., Sustainability (Switzerland) 13(1), 1-22 (2021)

13. D. Pica, F.H. Abanda, Advances in Science, Technology and Innovation, 345-350 (2021)

14. R. Kazaryan et al., E3S Web of Conferences 224, 02023 (2020)

15. N. Ni, Instrumentation Mesure Metrologie 19(6), 431-441 (2020)

16. E.A. Gusakova, A.S. Pavlov, IOP Conference Series: Materials Science and Engineering 953(1), 012079 (2020) 